\title{
Impact of Parental Acceptance-Rejection on Anxiety among Metropolitan Adolescents
}

\author{
Gayatri Raina $^{1}$, Priyanka Goyal ${ }^{2}$ \\ ${ }^{1}$ Assistant Professor, Department of Psychology, Himachal Pradesh University, Summer Hill, Shimla- \\ 171005 (H.P.) \\ ${ }^{2}$ Research Scholar, Department of Psychology, Himachal Pradesh University, Summer Hill, Shimla- \\ 171005 (H.P.) \\ Corresponding author: Gayatri Raina \\ Email-gayatri.raina3@gmail.com
}

\begin{abstract}
Background and Objectives: The present study was planned and executed with the aim to investigate the effect of parental acceptance- rejection (both mother and father) as perceived by adolescents on their anxiety level. The sample comprised of 300 students studying in ninth and tenth standard in private schools in Delhi. Methods: In order to study parental acceptance- rejection, Parental Acceptance-Rejection Questionnaire (PARQ) which consists of four dimensions (coldness, aggression, neglect and rejection) developed by Rohner was used separately for mother and father and for measuring anxiety, Mental Healthy Inventory (MHI-38) by Davies, Sherbourne, Peterson and Ware (1998) was administered. Correlation analysis and step wise regression analysis were carried out in order to study the effect of parental acceptance- rejection (both mother and father) on anxiety among adolescents.

Results: The results revealed that: as adolescent's perception of maternal and paternal coldness, aggression, neglect and rejection increases, adolescents become more anxious in nature and that mother's aggression emerged as significant predictor variables for anxiety among adolescents.

Conclusion: Parental warmth and nurturance acts as a buffer against the anxiety level of these adolescents. It may thus also be concluded that adolescents in metropolitan cities who do not perceive their parents as caring, affectionate or nurturing will experience higher level of anxiety.
\end{abstract}

Keywords: Adolescents, coldness, aggression, neglect, rejection, anxiety.

(Paper received $-11^{\text {th }}$ April 2018, Peer review completed $-10^{\text {th }}$ May 2018)

(Accepted $-24^{\text {th }}$ May 2018)

\section{INTRODUCTION}

Adolescence is considered as a period of transition from childhood to adulthood and it is important because many developmental changes occur during this time as has been mentioned in the previous sections. These changes include physical growth, new peer relationship with both the gender, emotional detachment from parents, enhancement of intellectual skills and so on. As a part of one's overall health, mental and emotional health or well-being is a necessary condition to enable one to manage one's life successfully. The adaptive experience, expression and regulation of emotion is increasingly being recognized as core feature of healthy intra and inter personal functioning across the lifespan. A critical aspect of child and adolescent development involves the ability to experience and express both positive and negative emotions [1]. Mental health is the emotional and spiritual resilience that allows one to enjoy life and to survive pain, suffering and 
disappointment [2]. Anxiety is one of the most common psychological disorders in school-aged children and adolescents worldwide [3].

Anxiety is associated with substantial negative effects on children's social, emotional and academic success [4]. Specific effects include poor social and coping skills, often leading to avoidance of social interactions [5], loneliness, low self-esteem, perceptions of social rejection, and difficulty forming friendships [6,7].

Adolescents of today's world are living in a world of competition where there is a cut throat competition in every sphere of life. "The theory of survival of the fittest" applies to each and every walk of the society. Adolescents today are living in an increasingly anxiety ridden atmosphere [8]. The adolescent period is often accompanied by new stress, behavioural changes and relationship problems and this affects psycho social development. Parental involvement in the lives of adolescent children facilitates young people to cope with stressors and do maintain physical and mental health [9].

Children experience anxiety as part of their normal development in daily life. However, sometimes, in some children, anxiety symptoms get exaggerated and become worse [10]. Research has suggested a connection between certain anxiety disorders and parental child-rearing styles. Arrindell and others [11] found that children with social phobias perceive rejection from their parents as compared to persons without an anxiety disorder. In a study by Grüner, Mûris, and Merckelbach [12], the researchers examined the association between parenting style and the development of anxiety symptoms in children with anxiety disorder. The researchers assessed emotional rejection involved in the development of childhood anxiety symptoms. They found significant and positive associations between parental rejection and severity of anxiety symptoms.

Mishra and Sharma [13] further demonstrated that perceived relationship with father, mother's love and one's appearance were associated with depression and anxiety among girls aged 12 to18. In general, girls tended to report higher adjustment difficulties than boys, but also more prosocial behaviour. McLeod, Wood and Weisz [14] revealed that higher levels of parental control were associated with more anxiety in children. The same has been witnessed in a sample of students aged 11to16 going to urban schools in Bangalore [15]. Asselmann and others [16] found that anxious adolescents reported low maternal autonomy support during childhood. Cooper-Vince, Pincus and Comer [17] found that intrusiveness, over involvement and high demandingness from parents were correlated with lack of confidence and lack of coping mechanisms which contributed to anxiety. Lungarini [18] found that more responsive fathers have children with low anxiety.

\section{METHODOLOGY}

The aim of the present research was to evaluate whether parental acceptance-rejection effects the anxiety among adolescents. For this purpose, Parental Acceptance Rejection Questionniare (PARQ) developed by Rohner [19] was used to measure the adolescent's perception about their parental acceptance and rejection, i.e., coldness, aggression, neglect and rejection and for evaluating anxiety among the selected sample of adolescents, Mental Health Inventory (MHI-38) developed by Davies, Sherbourne, Peterson and Ware [20] was administered.

\section{Sample}

A stratified random sampling approach was employed to select a total sample of 300 school children from ninth and tenth standard studying in private school in Delhi. The data from students were taken after obtaining permission from the school principal to conduct the study in their respective schools. The goal was to choose 150 students each from ninth and tenth class from two private schools in Delhi. The scales were administered on the students during their regular school time in their classes.

\section{Tools}

\section{Parental Acceptance-Rejection Questionnaire}

The Parental Acceptance-Rejection Questionnaire (PARQ) [19], is a self-report questionnaire designed to assess individuals' - both children's and adults' - perceptions of parental acceptance and rejection. The PARQ is characterized by its phenomenological orientation - that is, it asks children to interpret caregiver behaviour through their own personal and cultural lenses on four dimensions i.e. coldness, aggression, neglect and rejection. 
For the present study, a short form prepared by Rohner and Khaleque [21] was administered. It consists of 24 statements, that cover the four variables mentioned above and their scoring key is presented in Table 1. Individuals respond to statements on a 4-point Likert-type scale ranging from almost always true to almost never true. Higher scores indicated a higher level of perceived parental acceptance and lower scores indicate higher parental rejection. The reliability of the PARQ has been found to be remarkable in a variety of studies. Rohner [22] revealed a median coefficient of 0.91 (range $=0.83-0.96$ ) for the standard PARQ form. Validity studies on the PARQ have also been conducted and demonstrate remarkable results. Convergent and discriminant validity was shown with the PARQ scales correlating significantly with its respective validation scale [21]. The PARQ has been both utilized and cross-validated across several cultures, including transgender women of colour [23], Korean American adolescents [24], Turkish adults [25] and adolescents from Bangladesh, Estonia, India, Kuwait, Turkey, and the United States [26-27].

Table 1: Possible extremes and midpoints of Scale and Total-Test Scores of the PARQ

\begin{tabular}{|l|c|c|l|}
\hline Scales/Total Test & $\begin{array}{l}\text { Lowest } \\
\text { Possible } \\
\text { Scores }\end{array}$ & $\begin{array}{l}\text { Highest } \\
\text { possible } \\
\text { Scores }\end{array}$ & Component Items \\
\hline Coldness & 8 & 32 & $1,3,9,12,17,19,22,24$ \\
\hline $\begin{array}{l}\text { Aggression/Hostility } \\
\text { (AH) }\end{array}$ & 6 & 24 & $4,6,10,14,18,20$ \\
\hline $\begin{array}{l}\text { Neglect/Indifference } \\
\text { (NI) }\end{array}$ & 6 & 24 & $2,7,11,13^{*}, 15,23$ \\
\hline $\begin{array}{l}\text { Rejection } \\
\text { (Undifferentiated) (RU) }\end{array}$ & 4 & 16 & $5,8,16,21$ \\
\hline $\begin{array}{l}\text { Total (Composite) Test } \\
\text { (TC) (a) }\end{array}$ & 24 & $96(b)$ & \\
\hline
\end{tabular}

(a) Includes Warmth/Affection scale reverse scored

(b) 96 means maximum rejection (not maximum acceptance).

${ }^{*}$ Reverse scoring

\section{Mental Health Inventory (MHI-38)}

The Mental Health Inventory (MHI-38) was designed by Davies, Sherbourne, Peterson and Ware in 1998 and is a 38 item measure designed to assess the multi dimension nature of psychological well-being, including: anxiety, depression, loss of behavioural/ emotional control, general positive affect, emotional ties and life satisfaction [20]. The mental health inventory has a reported 0.93 Cronbach's alpha rating whereas its abbreviated version has 0.82 .

\section{STATISTICAL ANALYSIS}

The data obtained was entered using Microsoft Excel 2013 and analyzed using SPSS 16.0 Software. The Pearson chi square correlation test was used to find out the association of few of the personal factors with the levels of depression, anxiety and stress amongst the respondents.

\section{RESULTS}

For the purpose of analysing the results correlation and regression analysis were carried out. In order to look at the anxiety among adolescents mean and standard deviation were carried out and are presented in Table 2 . 
Table 2: Representing Distribution of Scores for Adolescent's Anxiety

\begin{tabular}{|c|c|c|c|c|c|}
\hline Variable & $\mathbf{n}(\%)$ & Mean & S.D. & Min. & Max. \\
\hline Anxiety & & 30.95 & 7.98 & 9 & 54 \\
Low Scorer $\left(<\_31\right)$ & $170(56.7)$ & & & & \\
High Scorer $(>31)$ & $130(43.3)$ & & & & \\
\hline
\end{tabular}

As can be seen from that Table 2 that approximately 43.3 per cent adolescents report to have high level of anxiety, whereas, 56.7 per cent report low anxiousness. It is evident from Table 3 there exists a significant and positive correlation between all the four variables of mother's acceptance-rejection, i.e., mother's coldness $(r=0.168, p<0.01)$, mother's aggression $(r=0.318, p<0.01)$, mother's neglect $(r=0.233, p<$ $0.01)$ and mother's rejection $(r=0.247, \mathrm{p}<0.01)$ and anxiety dimension of mental health. This indicates that as mother's coldness, aggression, neglect and rejection as perceived by adolescents increases, their anxiety level also increases.

Table 3: Representing Inter-Correlations of PARQ and Anxiety among Adolescents

\begin{tabular}{|l|c|}
\hline \multicolumn{1}{|c|}{ Parental Acceptance-Rejection } & Anxiety \\
\hline Mother's Warmth & $0.168^{* *}$ \\
\hline Mother's Aggression & $0.318^{* *}$ \\
\hline Mother's Neglect & $0.233^{* *}$ \\
\hline Mother's Rejection & $0.247^{* *}$ \\
\hline Father's Warmth & $0.124^{*}$ \\
\hline Father's Aggression & $0.222^{* *}$ \\
\hline Father's Neglect & $0.170^{* *}$ \\
\hline Father's Rejection & $0.231^{* *}$ \\
\hline \multicolumn{2}{|c|}{${ }^{*} \mathrm{p}<0.05, \mathrm{p}<0.01$} \\
\hline
\end{tabular}

It is further visible from Table 3 that there also exists a positive and significant correlation between all the four variables of father's acceptance-rejection, which includes father's coldness $(r=0.124, p<0.05)$, father's aggression $(r=0.222, p<0.01)$, father's neglect $(r=0.170, p<0.01)$ and father's rejection $(r=0.231, p<$ 0.01 ) and anxiety among adolescents. Thus, higher the father's coldness, aggression, neglect and rejection, higher is the anxiety level of adolescents. Thus, it can be concluded that as adolescent's perception of parental rejection in terms of coldness, aggression, neglect and rejection increases, adolescents' anxiety also increases.

Table 4: Stepwise Multiple Regression Analyses of Parental Acceptance-Rejection as Predictors of Anxiety among Adolescents

\begin{tabular}{|c|c|c|c|c|c|c|}
\hline $\begin{array}{c}\text { Independent } \\
\text { Variable }\end{array}$ & $\mathbf{r}$ & $\begin{array}{c}\text { Beta } \\
\text { Coefficient }\end{array}$ & $\mathbf{t}$ & $\mathbf{R}^{\mathbf{2}}$ & $\mathbf{R}^{2}$ Change & $\begin{array}{c}\text { F- Value } \\
\mathbf{R}^{\mathbf{2}} \\
\text { Change) }\end{array}$ \\
\hline $\begin{array}{c}\text { Mother's } \\
\text { Aggression }\end{array}$ & $0.318^{* *}$ & 0.318 & $5.781^{* *}$ & 0.101 & 0.101 & $33.418^{* *}$ \\
\hline
\end{tabular}

As is evident from Table 4, the only significant predictor variable for anxiety among the domains of parental acceptance-rejection is mother's aggression $(\beta=0.318, t=5.781, p<0.01)$. Thus, as adolescent's perception of their mother's aggression towards them increases, their anxiety also increases. Mother's aggression ( $\mathrm{F}=$ $33.418, \mathrm{p}<0.01$ ) accounted for 10.1 per cent of variance among anxiety variable. 


\section{DISCUSSION}

From the above presented results, it is apparent that the parental acceptance-rejection in terms of coldness, aggression, neglect and rejection both from mother and father has a positive correlation with anxiety among adolescents. Thus, if adolescents perceive both their parents to be cold, aggressive, neglecting and rejecting then they have significantly higher level of anxiousness. Furthermore, it is apparent from the results of regression analysis that of all the variables of parental acceptance-rejection only mothers aggression has emerged as a significant predictor of anxiety among adolescents.

The results of the study are incongruence with the mediation model as proposed by Rohner [19]. Gruner, Muris and Merckelback [12] examined the association between parenting style and the development of anxiety symptoms in children. The researchers assessed emotional rejection involved in the development of childhood anxiety symptoms. They found significant and positive association between parental rejection and severity of anxiety symptoms. Additionally, Shafi and Bhutto [28] found that adolescents high on parental rejection had higher level of anxiety.

Thergaonkar and Wadkar [29] found that democratic style of parenting and greater acceptance of parents among children may prevent anxiety. McLeod, Wood and Weisz [14] revealed that higher levels of parental control were associated with more anxiety among children.

Cooper-Vince and others [17] found that intrusiveness, over involvement and high demandingness from parents were correlated with lack of confidence and lack of coping mechanisms, which contributed to anxiety. Thus, it can be stated that both parental rejection and personality traits of an adolescent are important for his predisposition towards development of anxious behaviour. Mishra and Sharma [13] in their study demonstrated that mother's love is associated with anxiety among adolescents especially girls. Kaushik and Rani [30] have stated that perfectionist attitude of mothers is positively related with anxiety among adolescents. Asselmann and others [16] found that anxious adolescents reported low maternal autonomy support during adolescence. Even though, not much research has focused on direct role of maternal aggression on anxiety among adolescents, but from these studies it can be stated that if mothers are rejecting or aggressive then adolescents are anxious as they spend much of their time with mother at home, thus, aggression from mothers makes them fearful which leads to anxiety.

Waite and Cresswell [31] have further commented that parent who are critical or hostile towards their child, or the relationship is characterized by a lack of warmth, involvement, emotional support or reciprocity may lead to increase in child's sensitivity towards anxiety by undermining his or her ability to regulate emotions.

\section{CONCLUSION}

From the above discussed results of the present research work it can be concluded that adolescents in metropolitan cities who do not perceive their parents as caring, affectionate or nurturing will experience higher level of anxiety. Therefore, parental warmth and nurturance acts as a buffer against the anxiety level of these adolescents.

\section{REFERENCES}

1. Jersild AT, Brook JS, Brook DW. The psychology of adolescence. Macmillan Pub Co; 1978.

2. Heaven PC. The social psychology of adolescence. Palgrave Macmillan; 2001.

3. Cole DA, Peeke LG, Martin JM, Truglio R, Seroczynski AD. A longitudinal look at the relation between depression and anxiety in children and adolescents. J Consult Clin Psychol 1998;66(3):451-60.

4. Bögels SM, van Oosten A, Muris P, Smulders D. Familial correlates of social anxiety in children and adolescents. Behav Res Ther 2001;39(3):273-87.

5. Muris P, Field AP. Distorted cognition and pathological anxiety in children and adolescents. Cogn Emot 2008;22(3):395-421.

6. Rapee RM, Wignall A, Hudson JL, Schniering CA. Treating anxious children and adolescents: An evidencebased approach. New Harbinger Publications; 2000.

7. Silverman WK, Field AP, editors. Anxiety disorders in children and adolescents. Cambridge University Press; 2011. 
8. Beesdo K, Knappe S, Pine DS. Anxiety and anxiety disorders in children and adolescents: developmental issues and implications for DSM-V. Psychiatr Clin 2009;32(3):483-524.

9. Keller MB, Lavori PW, Wunder J, Beardslee WR, Schwartz CE, Roth J. Chronic course of anxiety disorders in children and adolescents. J Am Acad Child Adolesc Psychiatry 1992;31(4):595-9.

10. Bernstein GA, Borchardt CM, Perwien AR. Anxiety disorders in children and adolescents: A review of the past 10 years. J Am Acad Child Adolesc Psychiatry 1996;35(9):1110-9.

11. Arrindell WA, Kwee MG, Methorst GJ, Van der Ende J, Pol E, Moritz BJ. Perceived parental rearing styles of agoraphobic and socially phobic in-patients. Br J Psychiatry 1989;155:526-35.

12. Gruner K, Muris $\mathrm{P}$, Merckelbach $\mathrm{H}$. The relationship between anxious rearing behaviors and anxiety disorders symptomatology in normal children. J Behav Ther Exp Psychiatry 1998;30:27-35.

13. Mishra A, Sharma AK. A clinico-social study of psychiatric disorders in 12-18 years school going girls in urban Delhi. Indian J Community Med 2001;26:71-5.

14. McLeod BD, Wood JJ, Weisz JR. Examining the Association between Parenting and Childhood Anxiety: A Meta-analysis. Clin Psychol Rev 2007;27(2):155-72.

15. Reddy BK, Biswas A, Rao H. Assessment of mental health of Indian adolescents studying in urban schools. Malaysian J Paediatr Child Health 2011;17(2).

16. Asselmann E, Wittchen HU, Lieb R, Beesdo-Baum K. The Role of the Mother-Child Relationship for Anxiety Disorders and Depression: Results from a Prospective-Longitudinal Study in Adolescents and their Mothers. Eur Child Adolesc Psychiatry 2014;24(4):451-61.

17. Cooper-Vince CE, Pincus DB, Comer JS. Maternal Intrusiveness, Family Financial Means, and Aanxiety Across Childhood in a Large Multiphase Sample of Community Youth. J Abnorm Child Psychol 2014;42:42938.

18. Lungarini A. Parenting Styles and Their Relationship with Anxiety in Children. Thesis Submitted for Completion of Master's Degree. University of Rhode Island ; 2015.

19. Rohner EC. Perceived Parental Acceptance-Rejection and Children's reported Personality and Behavioral Dispositions: An Intra-cultural test. Behav Sci Res 1980;15:81-8.

20. Davies S, Heyman I, Goodman R. A population survey of mental health problems in children with epilepsy. Dev Med Child Neurol 2003;45(5):292-5.

21. Rohner RP, Khaleque A. Parental acceptance-rejection questionnaire (PARQ): Test manual. Handbook for the study of parental acceptance and rejection; 2005

22. Rohner RP, Pettengill SM. Perceived parental acceptance-rejection and parental control among Korean adolescents. Child Dev 1985;1:524-8.

23. Koken JA, Bimbi DS, Parsons JT. Experiences of familial acceptance-rejection among transwomen of color. J Fam Psychol 2009;23(6):853-60.

24. Kim E. Psychological adjustment in young Korean American adolescents and parental warmth. J Child Adolesc Psychiatr Nurs 2008;21(4):195-201.

25. Varan A, Rohner RP, Eryuksel G. Intimate partner acceptance, parental acceptance in childhood, and psychological adjustment among Turkish adults in ongoing attachment relationships. Cross-Cultural Res 2008;42(1):46-56.

26. Rohner RP. Perceived teacher acceptance, parental acceptance, and the adjustment, achievement, and behavior of school-going youths internationally. Cross-Cultural Res 2010;44(3):211-21.

27. Rohner RP, Khaleque A. Testing central postulates of parental acceptance- rejection theory (PARTheory): A meta- analysis of cross- cultural studies. J Fam Theory Rev 2010;2(1):73-87.

28. Shafi $\mathrm{K}$, Bhutto $\mathrm{ZH}$. Maladaptive parental styles and vulnerability to anxiety in adulthood. Pakistan Journal of Psychology 2006;37(1):63-74.

29. Thergaonkar NR, Wadkar AJ. Relationship between Test Anxiety and Parenting Style, Journal of Indian Association for Child and Adolescent Mental Health 2007;3(1):10-12.

30. Kaushik N, Rani S. A Comparative study of achievement motivation, home environment and parent child relationship of adolescents. J Psychological Res 2005;49:189-94.

31. Waite P, Creswell C. Observing Interactions between Children and Adolescents and their Parents: The Effects of Anxiety Disorder and Age. J Abnorm Child Psychol 2015;43(6):1079-91.

$* * * * * * * * * * * * * * * * * * * * * * * * * * * * * * * * * * * *$

Acknowledgements - Nil

Conflict of Interest - Nil

Funding - Nil 